\title{
Farewell to the luck (and Mind) argument
}

\author{
Christopher Evan Franklin
}

Published online: 13 July 2010

(C) The Author(s) 2010. This article is published with open access at Springerlink.com

\begin{abstract}
In this paper I seek to defend libertarianism about free will and moral responsibility against two well-known arguments: the luck argument and the Mind argument. Both of these arguments purport to show that indeterminism is incompatible with the degree of control necessary for free will and moral responsibility. I begin the discussion by elaborating these arguments, clarifying important features of my preferred version of libertarianism - features that will be central to an adequate response to the arguments-and showing why a strategy of reconciliation (often referred to as "deliberative libertarianism") will not work. I then consider four formulations of the luck argument and find them all wanting. This discussion will place us in a favorable position to understand why the Mind argument also fails.
\end{abstract}

Keywords Free will - Moral responsibility - Libertarianism - Luck argument · Mind argument · Rollback argument · Robert Kane · Peter van Inwagen

\section{Introduction}

In this paper I seek to defend libertarianism about free will and moral responsibility against two well-known arguments: the luck argument and the Mind argument. Both of these arguments purport to show that indeterminism is incompatible with the degree of control necessary for free will and moral responsibility. ${ }^{1}$ I begin the

\footnotetext{
1 The relationship between these arguments is little discussed. The Mind argument received its name and taxonomy from van Inwagen's (1983, pp. 126-150) influential discussion. As discussed there, "the" Mind argument actually consists of three different families or strands of arguments, the first appealing to the notion of luck in order to establish indeterminism's incompatibility with free will and moral
}

C. E. Franklin $(\bowtie)$

Philosophy Department, University of California, Riverside, 900 University Ave,

Riverside, CA 92521, USA

e-mail: Cfran002@ucr.edu 
discussion by elaborating these arguments, clarifying important features of my preferred version of libertarianism-features that will be central to an adequate response to the arguments - and showing why a strategy of reconciliation (often referred to as deliberative (Clarke 2000) or soft (Mele 1999a) libertarianism) will not work. I then consider four formulations of the luck argument and find them all wanting. This discussion will place us in a favorable position to understand why the Mind argument also fails.

This paper constitutes an essential component in any defense of libertarianism, which maintains that indeterminism is necessary for free will and moral responsibility. If the luck or Mind argument is sound, then rather than indeterminism being necessary for free will and moral responsibility, its absence will be required. This worry has led many to conclude that libertarianism is incoherent: libertarianism, it is argued, confuses a sufficient condition (indeterminism) for the absence of free will and moral responsibility with a necessary condition for their presence. Before libertarianism can be considered as serious contender for the best theory of free will and moral responsibility, it must be vindicated of this charge.

\section{The luck (and Mind) argument}

When people consider the various threats to the existence of free will and moral responsibility, notions like determinism, genetics, and social environment will immediately spring to mind. However, when you inform them that there is a long, venerable line of philosophers who think that indeterminism threatens the existence of free will and moral responsibility, they often respond with puzzlement. Isn't indeterminism a refuge for free will and moral responsibility? Doesn't indeterminism provide the needed independence from the past and environment, allowing the world to be a garden of forking pathways and we the captains who can select among its many diverging paths? But once we realize that indeterminism appears to be linked with luck and randomness, worries begin to emerge. If indeterminism entails luck and randomness, then indeterminism does indeed appear to be incompatible with free will. ${ }^{2}$ Presumably actions that are merely a matter of luck cannot be free actions-perhaps such events cannot be actions at all. Moreover, there seems to be an inverse relation between luck and control: the more an action is subject to luck, the less it is under our control, and the more an action is under our control, the less it is subject to luck. Luck and control thus appear to exclude each other: an action cannot be both wholly a matter of luck and wholly under our control. It is because indeterminism is frequently thought to smuggle in luck that many have thought that indeterminism threatens free will and moral responsibility.

\footnotetext{
Footnote 1 continued

responsibility. This naturally might lead one to view the luck argument as a species of the Mind argument. I have, however, opted, as have others (Finch and Warfield 1998), to treat 'the Mind argument' as simply the third strand of the Mind argument (van Inwagen 1983, pp. 142-150), thus treating the luck and Mind arguments as distinct.

${ }^{2}$ I will drop 'randomness' from now and only use 'luck' since this notion has received the most attention.
} 
That luck is contrary to control is a commonplace in our thought. People constantly argue about how much luck as opposed to skill is involved in poker. What cards one is dealt is presumably a matter of luck: one has no control over it (assuming one is not cheating). However, whether we win the hand with the cards we are dealt is not (usually) merely a matter of luck, since we do have some control over how we play our hand. Do we bet big first or slow play our cards hoping to trap our opponents? How well do we read our opponents' hands? Our success will greatly depend on how well we exercise these abilities.

Often in the context of sports, we contrast the skill and control of a player with luck. We might say, "He just got a lucky punch in", or "That was a lucky shot." In these cases we are calling into question the degree of control the athlete exercised over some result. By claiming that he got lucky in bringing about the result, we are claiming that the athlete lacked a sufficient degree of control for the result to be truly credited to him. The result was not genuinely up to him; rather he just got lucky.

This intuitive connection between luck and control is one reason that many have concluded that indeterminism diminishes or eliminates control. It seems that indeterministic events are, by nature, chancy, and this seems to imply that any of our actions that are undetermined are matters of luck for us. The luck argument (Haji 1999, 2001; Hobart 1934; Hume 2000; Mele 1999a, b, 2006; van Inwagen 2000) seeks to regiment these intuitions about luck and control into a rigorous argument that purports to show that free will and moral responsibility are incompatible with indeterminism. The closely related Mind argument (van Inwagen 1983, pp. 142-150) also purports to show that indeterminism is incompatible with free will and moral responsibility, but unlike the luck argument eschews any appeal to the notion of luck. The fundamental aim of this paper is to show that the luck argument is unsound and, secondarily, that the Mind argument is unsound. Consequently, the focus of the present and following sections will be the luck argument. In the final section of the paper I will turn my attention to the Mind argument, showing that it fails for very similar reasons as the luck argument.

It is a general assumption of libertarianism that at least some free actions must be undetermined. ${ }^{3}$ Since control comes in degrees it is hard to nail down the luck argument in full generality. One might maintain, for example, that indeterminism does not preclude the possibility of exercising any control over our actions, but instead diminishes our control so severely that we never freely perform any of these actions. Nonetheless, the core of this problem can be characterized by the following two claims:

(i) If an action is undetermined, then it is a matter of luck

(ii) If an action is a matter of luck, then it is not free.

(i) remains silent on whether an undetermined action is wholly or partly a matter of luck, and (ii) remains silent on whether luck precludes the possibility of an agent

\footnotetext{
${ }^{3}$ It is open to libertarians to maintain that some determined actions are also free so long as the freedom of these actions derives from earlier free actions that were undetermined. In this paper I will limit my attention to actions that do not derive their freedom from earlier actions-so called "underivatively" free actions.
} 
exercising any control, or merely the degree of control required for free will and moral responsibility. ${ }^{4}$ Various formulations of the luck argument differ on how they fill in and defend these two claims. For example, some define 'luck' as an absence of a certain kind of explanation, and then argue that undetermined events are a matter of luck because they lack the relevant kind of explanation. Other versions leave luck undefined and argue that undetermined action is a matter of luck in a rather obvious, intuitive sense.

The luck argument is especially troubling for libertarians who maintain not only that free will and moral responsibility are compatible with indeterminism, but that they require it. ${ }^{5}$ Libertarians maintain that determinism precludes the possibility of agents possessing free will and hence from being morally responsible, and thus that indeterminism is necessary for furnishing agents with enhanced control-the kind of control that is necessary for free will and moral responsibility. Indeterminism must occur somewhere near the moment of action for agents to possess free will and moral responsibility either because indeterminism itself enhances control, or because indeterminism is necessary for some further feature (for example an agentcausal power), and it is this further feature that secures enhanced control. Indeterminism thus plays a central role in libertarian answers to the problem of enhanced control (Franklin n.d.a; Pereboom 2001, pp. 38-41) - the problem of explaining how libertarian accounts secure more control than rival compatibilists theories.

According to the luck argument, however, once we consider indeterminism's connection with luck, we will see that libertarians are mistaken: rather than enhancing control, indeterminism precludes the necessary degree of control for free will and moral responsibility. Indeed, if the luck argument is sound, then libertarianism is incoherent. Libertarianism entails that we sometimes perform free, undetermined actions, and so if premises (i) and (ii) of the luck argument are true, it follows that some of these undetermined actions are both free and unfree. It is for precisely this reason that many have questioned the coherence of libertarianism (cf. Double 1991; Smilansky 2000). This is a serious problem indeed: by locating indeterminism at the moment of action, libertarians purportedly introduce luck which results in a diminution or elimination of control.

The problem of enhanced control and the luck argument point to a tension within libertarianism: indeterminism seems relevant to enhancing control only if it is located at the moment of action. But if indeterminism is located at the moment of action, then control is diminished. Libertarians may not be satisfied with the degree of control that compatibilist accounts secure, but it turns out, according to the luck argument, that their own accounts secure even less control.

\footnotetext{
${ }^{4}$ This is not quite right. I assume it is analytic that agents exercise some control over their actions. In light of this, the term 'action', as it occurs in (i) and (ii), would seem to entail that the agent exercises some control over it. To avoid this we could replace 'action' with 'event' so as to remain neutral about the degree of control the agent possessed or lacked over these undermined events. As far as I can tell nothing important turns on this subtlety.

5 The luck argument is also troubling for compatibilists who think that neither determinism nor indeterminism is a threat to free will and moral responsibility (see Fischer and Ravizza 1998, pp. 253-254).
} 
Before turning to my criticism of the luck (and Mind) argument, I will sketch my own preferred account of libertarianism. The account is a reductive, event-causal theory insofar as it analyzes the role of the agent solely in terms of events and states of the agent, eschewing any appeal to irreducible agent-causation. In this way it is similar to Kane's (1996) influential theory of libertarianism. However, a vital difference between mine and Kane's theory concerns the role and location of indeterminism, and, as we will see, it is precisely this difference that allows my theory to avoid some of the more worrisome formulations of the luck argument (it also helps to show why the Mind argument fails). After developing my theory and distinguishing it from Kane's, I consider an often discussed libertarian strategy of compromise for resolving the problem raised by the luck argument, and demonstrate that this strategy cannot succeed. I then turn to the luck argument itself and consider four different formulations: the Hume-Hobart formulation, the ensurance formulation, the rollback formulation, and the explanatory formulation. After showing that none of these formulations of the luck argument are sound, I finally turn to the Mind argument and argue that it too poses no serious threat to the coherence of libertarianism.

\section{Kane and the luck argument}

Event-causal theories of action seek to analyze the notion of an agent making something happen solely in terms of certain events and states making something happen. These accounts are certainly not without their problems, but, these problems notwithstanding, event-causal accounts are widely considered to be the best analysis of action available. ${ }^{6}$ According to my theory, actions are events that have a distinctive causal history: what distinguishes an action (my raising my arm) from mere behavior (my eye's twitching) is how these events are brought about. An action is an event that is caused, in the appropriate way, by agent-involving mental events. Taking an overly simplistic example, what makes my raising my arm an action is that it is brought about, in the appropriate way, by certain agent-involving mental events, such as my reasons for raising my arm. More must be said (What makes a causal pathway "appropriate"? Which mental events are involved in the production of action? In what way must agent's be "involved" in the specified events?), but this sketchy account will suffice for present purposes. An agent's exercising control over some event, then, consists in that event's being caused, in the appropriate way, by agent-involving mental events. Event-causal libertarians maintain that, crucial to transforming a mere action into a free action is that the mental events that caused the action do so nondeterministically. A necessary condition for my freely raising my arm is that this action was nondeterministically caused, in the appropriate way, by agent-involving mental events.

Libertarians offer different reasons for why free action requires nondeterministic causation. My own favored explanation is that by locating indeterminism in the

\footnotetext{
${ }^{6}$ See Bishop (1989) and Velleman (2000) for helpful introductions (as well as potential solutions) to the difficulties facing event-causalists.
} 
causal sequence leading from the non-actional mental events (reasons, intentions, desires, beliefs) to choice, we afford agents with the opportunity to do otherwise (Franklin n.d.a). In addition to bringing the action about that they actually did, the agent also had the opportunity to bring about a different action, or perhaps no action at all. Suppose I am deliberating about whether to keep my promise to my friend or to break it: I have reasons that favor keeping the promise and reasons that favor breaking it. After much deliberation, I come to decide to break the promise. According to my version of event-causal libertarianism, if this action was free, then it was nondeterministically caused, in the appropriate way, by agent-involving mental events, such as the agent's intention to make up his mind and his reasons that favored breaking the promise. Importantly, since the causation was nondeterministic, it was possible, given the past and laws, that I not make this decision. It was possible that I had continued to deliberate or decided to keep the promise. In this alternative case, had I decided to keep the promise, then this action would have been nondeterministically caused by different reasons, reasons that favored my keeping the promise. More needs to be said in defense of this theory, but again this sketch will suffice for present purposes.

Nearly all recent formulations of the luck argument have been directly aimed at undermining Kane's $(1985,1996)$ event-causal libertarian account. ${ }^{7}$ Because of this, it is worth noting a central difference between our theories, a difference that will make my theory a harder target for the luck (and Mind) argument.

Although our accounts have many similarities, and in many ways I am indebted to Kane, there is at least one important difference. To understand this difference we need to consider the role that conflict of will plays in Kane's theory. According to Kane, there are various episodes in our lives in which we must make a choice between incommensurable alternatives, as for example, between moral duty and self-interest. The usual case discussed concerns a businesswoman who comes across a man who has just been mugged in an alley (Kane 1996, p. 126). She must decide between the mutually exclusive and exhaustive options of helping this person or attending an important business meeting. She knows there are moral reasons that favor helping this person, but also that if she misses the meeting her career aspirations will suffer a major setback. On Kane's account, the businesswoman makes an effort of will to help the man in need. ${ }^{8}$ This effort of will is indeterminate and so it is possible, given the past and the laws, that the effort either succeed and culminate in a choice to help the man, or fail and result in a choice to go on to the business meeting. But either way, given the conflict, the businesswoman will do what she wants to do, and will do what she does for reasons she has. Indeterminism, on Kane's account, occurs between the effort of will and choice.

\footnotetext{
7 Haji (2001) and Mele (1999b) are cases in point. In fact, most formulations exclusively have Kane's account in mind. This is not because there is something particularly implausible about Kane's account, but because Kane, admirably, more thoroughly than others develops a positive and detailed account of libertarianism.

${ }^{8}$ In Kane (1999) he doubles the effort: the businesswoman makes an effort to resist temptation and she makes an effort to go to the business meeting. Although this move may help Kane in avoiding the argument from luck, it seems to do so only by introducing a deep incoherence in the agent. I will ignore this move by Kane since it does not affect the main difference between our two accounts.
} 
One question that naturally arises concerns what kind of thing this "effort of will" is? Is it an action? A desire? As Kane repeatedly speaks of an agent "making an effort of will", it seems natural to construe this effort of will as a kind of action, something the agent does. If this is correct, it turns out that Kane locates indeterminism between one action, an effort of will, and later actions that this effort of will generates, such as choices, overt action, and so on. ${ }^{9}$ The businesswoman does something — makes an effort of will—which might lead to one choice or might lead to another. Indeterminism at this juncture may indeed appear to introduce an element of luck: the businesswoman's best effort leaves open what she will do and this makes it seem like her subsequent choice is (merely) a matter of luck.

In contrast to Kane's account, my account locates indeterminism between nonactional mental states and choice: indeterminism occurs between our reasons, desires, beliefs, preferences, etc.—-states which lead to action-and choice and overt action. It is Kane's location of indeterminism, I believe, that makes his account especially susceptible to the luck argument. In fact, I believe that this feature of Kane's account has continued to kindle the flame of this argument. Kane's theory is the centerpiece of libertarianism and consequently any problem that Kane's account faces is likely to lead us to think that this is a problem for libertarianism tout court.

In order to understand how Kane's account generates worries about luck, consider a case in which I try my best to resist the temptation to break a promise and make an indeterminate effort of will to resist this temptation. Once I have made this effort, there is nothing left for me to do in order to influence the outcome-either the effort shall result in a choice to fulfill the promise or a choice to break it. It is reasonable to suppose that indeterminism introduces an element of luck here: the agent does all he can, and then just has to wait to see what the outcome is. Even though I may exercise some degree of control over the outcome, indeterminism appears to diminish my control. It seems that, if my effort would have deterministically brought about my choice to keep the promise, then I would have exercised more control over the outcome.

The point here is not that Kane's account fails to secure the necessary degree of control for free will and moral responsibility, but that he faces a unique charge of luck because he places indeterminism between actions. ${ }^{10}$ Kane's account is relevantly similar to the athlete examples above in a way that my own account is not. In those examples, the idea was that after the athlete did his best to secure a certain outcome, it was still undetermined what might happen. Everything the athlete did left open what result he would bring about. If this is correct, an element of luck appears to creep in. However, my account is perfectly compatible with every choice or action deterministically bringing about later choices, actions, and consequences. I do not require scenarios in which everything the agent does leaves open what will come about. Rather I require that, at least for some actions,

\footnotetext{
${ }_{9}$ I will use the term 'action' equivocally, sometimes to refer to a general category that includes mental events such as choices and decisions, and other times to refer to overt, publicly observable events as a distinct from these private mental events. However, context will make clear which sense of 'action' I have in mind.

${ }^{10}$ See Kane (1996, Chaps. 9-10) for his response to the luck argument.
} 
everything the agent does not do, all the non-actional elements-such as his character, education, up-bringing, reasons, desires, etc.-leave open what he does.

I will return to this point below as it will afford me avenues of response to the various versions of the luck argument that are unavailable for Kane. But before turning to the luck argument itself, I want to show why a well-known libertarian strategy of reconciliation will not work.

\section{Deliberative libertarianism}

The luck argument gets off the ground because libertarians have traditionally required that some free actions be undetermined. This has led some philosophers (Dennett 1978; Fischer 1995; Mele 1999a) to suggest that libertarians should locate indeterminism earlier in the causal sequence leading to action. ${ }^{11}$ The idea behind these attempts is that libertarians can inoculate freedom against luck by locating indeterminism at a time when we do not think agents normally exercise any control. If we place indeterminism at a moment when the agent exercises no control, then, of course, control is not diminished: you cannot diminish what you never had. Deliberative libertarian accounts, as Randolph Clarke (2000) has named them, locate indeterminism within the deliberative process rendering the agent's all things considered judgment undetermined. On this account, whether certain considerations come to mind is undetermined, and hence the all-things-considered judgment that the agent arrives at is undetermined. Some considerations come to mind and lead the agent to judge that it is best to $\varphi$. However, it was possible, given the past and laws, that certain other considerations came to mind, and if these considerations had come to mind, then the agent would have judged that it is best to $\psi$. But, and this is crucial, the all-things-considered judgment causally determines the subsequent decision. At the time of deliberation, then, it is undetermined what decision the agent will make since it is undetermined what all-things-considered judgment the agent will make. But once this judgment is in place, only one decision is causally possible.

According to deliberative libertarians, we normally assume that agents are not in control of every consideration that comes to mind and thus, supposing that indeterminism does indeed crowd out control, locating indeterminism at this juncture in the deliberative process does not necessarily diminish the degree of control that the agent otherwise would have had (Mele 1999a, p. 289). ${ }^{12}$ At the point where the agent exercises his agency, there is no indeterminism and hence no diminution of control. In explaining the motivation behind such a view Alfred Mele writes, "Furthermore, a kind of internal indeterminism is imaginable that limits our

\footnotetext{
11 I say 'philosophers' rather than 'libertarians' to make it clear that no libertarian, to my knowledge, makes this move. I believe this fact is revealing. Deliberative libertarianism, as I will argue below, is no version of libertarianism at all.

12 I am inclined to think that agents are very active throughout the deliberative process, bringing considerations to mind, evaluating them, prolonging the process and so on. If this is correct, then placing indeterminism here may be no less of a threat to freedom than locating it at the termination of the deliberative process. But for the sake of argument, I will grant the deliberative libertarian his assumption.
} 
control only in a way that gives us no less control than we would have on the assumption that determinism is true, while opening up deliberative outcomes" (1999a, p. 289). The promise of these accounts is to secure alternative possibilities without introducing luck. They supposedly make good on this promise by locating indeterminism close enough to action to have some relevance, but far enough away that it does not threaten control.

Deliberative libertarianism, however, is a near-sighted solution to the luck argument. By locating indeterminism during the deliberative process, they may avoid the possibility of indeterminism diminishing control, but only at the expense of indeterminism's exclusion from being relevant to enhancing control. A libertarian theory of free will must provide adequate answers to both the problem of enhanced control and the luck argument. I have argued elsewhere (Franklin n.d.a) that indeterminism must be located at the moment of choice in order for libertarians to secure enhanced control. Deliberative libertarianism avoids the luck argument only at the expense of falling prey to the problem of enhanced control.

There is dilemma for libertarians lurking here: either indeterminism is located at the moment of action or it is not. If it is not located at the moment of action, then there is no reason to think that it diminishes control, but there is also no reason to think that it is relevant to enhancing control. If indeterminism is located at the moment of action, then it is positioned to be relevant to enhancing control, but, as the luck argument contends, it actually ends up diminishing control. Libertarians must tackle one horn or the other, showing, on the one hand, how indeterminism could be located earlier than the moment of action and yet still be relevant to enhancing control, ${ }^{13}$ or, on the other hand, why the luck argument fails. What they cannot do is precisely what the deliberative libertarian does: simply accept the first horn. The deliberative libertarian admits that indeterminism during the deliberative process is not relevant to enhancing control, but tries to console us by pointing out that at least it does not diminish control.

Often deliberative libertarians will admit that their accounts fail to secure any more control than rival compatibilist accounts (thus acquiescing to the first horn), but go on to argue that their accounts do secure other items of value and that this might lead us to reasonably prefer libertarianism to compatibilism. For example, we might value a kind of independence from the past that can only be secured if indeterminism occurs somewhere near the moment of action, such as the deliberative process (cf. Clarke 2000; Mele 1999a). Mele describes Wilma, a person who is attracted to such an account, as someone who leaves it open whether "freedom and moral responsibility are compatible with determinism, but maintain that the falsity of determinism is required for more desirable brands of these things"

\footnotetext{
${ }^{13}$ One might try to do this by arguing that indeterminism occurs during preference formation and it is preference formation, rather than choosing and acting in accordance with our preference, that is the true loci of control (see Ekstrom 2000, 2003). Alternatively, one might argue, like the deliberative libertarian, that indeterminism occurs during the deliberative process, but, unlike the deliberative libertarian, that this process is the loci of agential-control. Either of these strategies may succeed, but only at the expense of the deliberative libertarian strategy. Remember, their strategy was to locate indeterminism at a moment when we normally think agents do not exercise any control. Consequently, deliberative libertarians must argue that indeterminism occurs at a moment when the agent exercises no control and yet is still relevant to enhancing control. It is this latter option that I believe is hopeless.
} 
(1999a, p. 286). This position does not require indeterminism for freedom and moral responsibility, but rather for "more desirable" kinds of freedom and moral responsibility. ${ }^{14}$

These comments however make it clear that deliberative "libertarianism" is no version of libertarianism at all. Libertarianism entails incompatibilism about determinism and free will and moral responsibility, yet Mele makes it clear that deliberative libertarianism has no such entailment. Deliberative libertarianism "[leaves open whether] freedom and moral responsibility are compatible with determinism", as Mele writes. But this does not mean that deliberative libertarianism is a form of compatibilism. Both compatibilists and incompatibilists are decidedly not agnostic about the (in)compatibility of determinism with freedom and responsibility, and for this very reason they cannot be deliberative libertarians: once one takes a stand on the compatibility issue one ceases to be a deliberative libertarian. But it is also precisely for this reason that deliberative libertarianism is not a form of libertarianism. It is no wonder, then, that no libertarians actually endorse this position: deliberative "libertarianism" is not compatible with libertarianism.

Deliberative libertarianism, consequently, is not an avenue of response for libertarians: it is a concession of defeat. It simply accepts the first horn of the dilemma and tries to console us that it is not so bad. A true libertarian answer, one that is actually compatible with libertarianism, is forced to deny one of the horns. As I have argued elsewhere (Franklin n.d.a) that indeterminism is relevant to enhancing control only if it is placed at the moment of action, I am saddled with showing that the luck argument fails to demonstrate that indeterminism diminishes control-a task to which I will now turn to.

\section{The Hume-Hobart formulation}

Some of the earliest discussions of the luck argument are found in Hume's Treatise and Enquiry, where he argues not only that free will ("liberty") is compatible with determinism, but that it actually entails it. Hume writes, "According to my definitions, necessity makes an essential part of causation; and consequently liberty, by removing necessity, removes also causes, and is the very same thing with chance" (2000, pp. 261-262). Libertarians, requiring the absence of necessity for liberty, end up, according to Hume, eliminating causation and thus introducing luck. If we assume that causation essentially involves a kind of necessitation such that, given the cause, the effect necessarily follows, then indeterminism, which is simply the absence of this kind of necessitation, is also the absence of causation. Admittedly, it is difficult to see how someone can be said to have controlled an

\footnotetext{
14 I take Mele's idea to be that the deliberative libertarian assumes that freedom and moral responsibility are both threshold and degree concepts. The deliberative libertarian leaves open whether determinism is compatible with meeting the threshold conditions for freedom and moral responsibility. What they insist on is that indeterminism secures higher degrees of freedom and responsibility that are of value for reasons other than that they are necessary for freedom and responsibility.
} 
event if nothing, let alone the agent, brought it about. ${ }^{15}$ If Hume is right about causation, it looks like "actions" on libertarian accounts just happen-in other words they appear to be simply a matter of luck.

Hobart, picking up in the twentieth century on Hume's insight, claims that on libertarian accounts, "This volition of the self causes the physical act but it is not in its turn caused, it is 'spontaneous.' To regard it as caused would be determinism." (1934, p. 4). ${ }^{16}$ Libertarians, in requiring the absence of necessitation, unwittingly require the absence of causation. This renders these so-called "free acts" mere chance occurrences: an event that simply happens without anyone or anything bringing it about.

This version of the luck argument has the most potential bite. If Hume and Hobart are correct that undetermined events are uncaused, then it does indeed seem that undetermined actions are a matter of luck. Thus we have premise (i) from above. Moreover, it is reasonable, from an intuitive standpoint, to assume that if an action is a matter luck, then it is not a free action. Therefore, libertarianism is incoherent: it entails that some unfree actions are also free actions.

Fortunately for the libertarian, it is now widely understood that causation can exist in the absence of necessitation: one event can cause another even though it does not necessitate it. I can hardly do better than point the reader to G. E. M. Anscombe's brilliant work, 'Causation and Determination' (1971), in which she forcefully argues that there has never been good reason to think that the very possibility of causation requires necessitation. Quantum mechanics has also played a helpful role in allowing us to see this point. We are hard pressed to give up the idea that every event has a cause. But according to the standard interpretation of quantum mechanics, some events are undetermined. For most, this discovery is tantamount to the discovery that undetermined events can have causes.

Once necessitation and causation are pried apart, the Hume-Hobart formulation crumbles. The key premise in their argument was that an undetermined action is an uncaused action. But this is false: an undetermined action can also be a caused action. Without this premise they provide no reason for thinking that an undetermined action is a matter of luck. But this has not kept others from thinking that Hume's fundamental point about the link between indeterminism and luck was correct. Let us now turn to other formulations that attempt to explicate this link.

\section{The ensurance formulation}

The ensurance formulation of the luck argument has been most clearly and forcefully presented by Haji $(1999,2001)$. The core idea beyond this formulation is that if an agent performs an undetermined action $\varphi$ at $t$, then she could not have ensured or guaranteed that she $\varphi$-ed rather than $\psi$-ed at $t$. I believe that something

\footnotetext{
15 However, see Ginet (1990) and McCann (1998) for elaborate defenses of the possibility of agents possessing a robust degree of control over uncaused events.

16 Ayer (1954), Nowell-Smith (1948), and Smart (1961) all make similar claims. In fairness to these authors, libertarians, at this time, often claimed that free action was uncaused (see for example Campbell 1951).
} 
like this thought is behind most philosophers' suspicion that indeterminism is inimical to control. According to this formulation of the luck argument, indeterminism prevents agents from having the power to guarantee a particular outcome: agents try their best, but they cannot ensure what they will do. From this lack of "ensurance," it is inferred that the action in question is a matter of luck, and thus we have (i) from above. As with the Hume-Hobart formulation, it seems that if an action is a matter of luck, then the action is not free. It follows, therefore, according to libertarianism, that some actions are free and unfree.

The crucial premises of this formulation are, (1) undetermined actions are not ensured, and (2) if an action is not ensured, then the action is a matter of luck. As we will see, both of these premises are problematic. Let us begin by considering (1). According to Haji, an agent can ensure that he performs an action $\varphi$ only if he has antecedent control over $\varphi$-that is control "to see to it that...he [ $\varphi$-s] rather than that he does not..." (2001, p. 190). But this is not very informative. There is a natural reading of this gloss which makes it clear that agents can have this kind of control even over undetermined actions. It is easiest to understand this if we replace control with power. Haji admits that agents can have the power to bring about an undetermined action $\varphi,{ }^{17}$ but denies that they can have the power to see to it that they bring about $\varphi$ rather than some other action $\psi$. But this rings false. If I have the power to bring about $\varphi$, then I have the power to bring about $\varphi$ rather than $\psi$. After all, I have the power to bring about $\varphi$, and my bringing about $\varphi$ is sufficient for my bringing about $\varphi$ rather than $\psi$; so I have the power to bring about $\varphi$ rather than $\psi$. Consequently, if antecedent control simply amounts to the power to make it the case that I $\varphi$ rather than $\psi$, we have no reason to think that indeterminism is incompatible with it.

I have my doubts, however, that this is the kind of control Haji intends antecedent control to capture. Rather, I suspect he has in mind something more like the following: An agent $\mathrm{S}$ has antecedent control over an action $\varphi$ at $t_{2}$ just in case $\mathrm{S}$ has the power at $t_{1}$ to $\psi$ at $t_{1}$ and if he $\psi$-ed at $t_{1}$, then $\psi$ would deterministically bring about $\varphi$ at $t_{2}$. For example, I have antecedent control over my ordering a salad at some later time $\mathrm{t}$ only if I have the power now to do something that would deterministically bring about my ordering a salad at $t$. It is this kind of control, according to Haji, that we cannot have over undetermined actions.

Haji is not the only one who thinks that libertarians cannot secure antecedent control. Interestingly, even Kane seems to agree (as well as O'Connor (2000, p. 32)). Kane claims "the ability to be in, or bring about, conditions such that one can guarantee or determine which of a set of outcomes is going to occur before it occurs, whether the outcomes are one's own actions, the actions of others, or events in the world generally" is something that libertarian agents ${ }^{18}$ cannot have (Kane 1996, p. 144). ${ }^{19}$ Kane's strategy is to concede that libertarian agents lack antecedent control, but deny that this entails that their actions are a matter of luck.

\footnotetext{
17 I defend Haji's assumption in Sect. 7.

18 By 'libertarian agents' I simply mean 'agents who satisfy libertarianism'.

19 He reaffirms this view in Kane (1999, pp. 237-238).
} 
Haji and Kane, however, are mistaken: agents can possess antecedent control even over undetermined actions. Consider $\mathrm{S}$ who brings about an undetermined action $\varphi$ at $t_{2}$. S had antecedent control over $\varphi$ only if there is something he could have done at an earlier time $t_{1}$ that would have deterministically brought about $\varphi$ at $t_{2}$. It is a mistake to assume that $\varphi$ 's being undetermined somehow stands in the way of $\mathrm{S}$ possessing this kind of control. There is nothing contradictory in supposing that $\mathrm{S}$ had the power at $t_{1}$ to $\psi$ at $t_{1}$, and if he $\psi$-ed at $t_{1}$, then $\psi$ would have deterministically caused $\varphi$ at $t_{2}$, but, as things actually stand, S did not exercise this power, and consequently his $\varphi$-ing at $t_{2}$ was undetermined. Return to the salad case. As things actually stand, my ordering a salad at $t_{2}$ was undetermined, but I nonetheless possessed antecedent control over this action. I possessed this kind of control because I had the power at $t_{1}$ to make a resolution to order a salad, and if I made the resolution at this earlier time, then it would have deterministically brought about my ordering a salad at $t_{2}$. Consequently, premise (1) is false: agents can possess antecedent control over undetermined actions.

It is possible, then, for agents to possess antecedent control over undetermined actions. What is impossible is for them to exercise this control over undetermined actions, for exercising antecedent control over an action requires that one deterministically bring it about. Possessing antecedent control and exercising antecedent control, however, are different things and it is only by conflating them that it appears that agents must lack antecedent control over undetermined actions.

But this distinction suggests a different reading of premise (1). Libertarians claim that we have free will only if some of our actions are undetermined. Consequently, since exercising antecedent control over an action requires that the action is deterministically caused, libertarians must claim that we have free will only if we do not exercise antecedent control over some of our actions. Premise (1) can then be read not as a claim about possessing antecedent control, but about exercising it: undetermined actions are unensured because we cannot, qua undetermined actions, exercise antecedent control over them. ${ }^{20}$

Under this reading of the ensurance formulation, premise (1) is true, but only at the expense of rendering premise (2) implausible. Under the present reading, (2) asserts that an action $\varphi$ cannot be free unless we perform some earlier action $\psi$ that deterministically brings about $\varphi$ (i.e., unless we exercise antecedent control over $\varphi$ ). A dilemma arises for Haji at this point: either $\psi$ must itself be free or not. If $\psi$ must be free, then, as I will argue below, a vicious regress is initiated, thus making free action impossible. If $\psi$ does not need to be free, then Haji is saddled with the implausible claim that free actions is (or can be) deterministically brought about by unfree action.

It will be helpful to introduce two new notions: 'freely exercising antecedent control' and 'merely exercising antecedent control'. An agent freely exercises antecedent control over some action $\varphi$ only if she performs some earlier free action $\psi$ that deterministically causes $\varphi$. An agent merely exercises antecedent control over some action only if she performs some earlier action $\psi$ that deterministically brings about $\varphi$. Mere, as opposed to free, antecedent control does not require $\psi$ to be

\footnotetext{
${ }^{20}$ Haji himself seems to suggest this alternative understanding of premise (1) (see Haji 2001, p. 190).
} 
free. Under this new reading of (2), this premise entails that if an agent freely performed $\varphi$, then either she freely exercised antecedent control or she merely exercised antecedent control. I will now argue that both disjuncts are implausible, and, consequently, that the ensurance argument is implausible.

Consider the second disjunct first. According to this disjunct, whenever an agent performs a free action $\varphi$, she exercises mere antecedent control over $\varphi$. In other words, she performs some earlier action $\psi$ that need not be free and $\psi$ deterministically causes $\varphi$. But this seems dubious. Why should free action require that one performed an earlier action that deterministically brought it about? Compare two actions: one that is caused not by an earlier action, but by mental states of the agent and one that is caused by the agent's earlier action. Why is the second more conducive to freedom and responsibility? Suppose that the earlier action is one for which the agent is responsible, whereas the agent is not responsible for the earlier mental states. There is something plausible about the claim that the second action is one over which the agent exercises more control: it is caused by an earlier action that the agent is responsible for, whereas the other action is caused by states that the agent is not responsible for. But under this response, the second horn collapses into the first: we are now supposing that free action requires free antecedent control. I cannot see any other reason for thinking that free action must be caused by earlier actions of the agent, nor does Haji offer an alternative explanation. I conclude that the claim that free will requires mere antecedent control is simply unmotivated.

The claim that free action requires antecedent control gains plausibility only when we assume that free antecedent control is at issue. Premise (2) then commits Haji to the first horn. But this horn generates a vicious regress of free actions. Under this reading of premise (2), an agent's freedom over $\varphi$ entails that she freely exercised antecedent control over $\varphi$, and this in turn entails that she freely performed some earlier action $\psi$. $\psi$ is free, however, only if she freely exercised antecedent control over it, and this entails that she freely performed some yet earlier action. But in order to have freely exercised antecedent control over this earlier action, she must have performed a still yet earlier free action, and so on ad infinitum. Consequently, if freedom entails freely exercising antecedent control, then freedom entails that free agents have always been performing free actions.

On the first horn, in order to have freedom over any of our actions and thus to avoid luck, we must have always been performing actions. But this is not a tenable picture of agency. The origins of agency are certainly obscure, but we can be confident that none of our origins are similar to the agent in this story: we are finite agents and there was a time when we were not performing any actions, let alone free actions. Presumably there is some time (a moment or perhaps a segment of time) in our lives at which we perform an action(s) and there was no earlier time that we performed any action. It is hard to determine when the precise time is, but that need not concern us. The simple point is that it is necessarily false, at least for finite agents like us, that for every free action we perform, there was an earlier time that we performed an action (perhaps God is like this).

Freedom, according to premise (2), turns out to be impossible for agents like us. But (2) is implausibly strong: in order for us to be free and morally responsible for 
our actions (and thus avoid luck), we must have always been performing actions. But this doubtful in the extreme; at the very least it cries out for defense-a defense Haji never gives. The only way for Haji to avoid this regress is to deny that the earlier action, in virtue of which we exercised antecedent control over the later action, must be free; in other words he must turn back to the second horn in which freedom only requires mere antecedent control. But we have already seen that this requirement is unmotivated: why does performing an earlier unfree action enhance control over later actions? As this exhausts the possible options for Haji, we have good reason to reject (2).

But for those who are inclined to persist in endorsing (2), notice that the impossibility of our being free has nothing to do with indeterminism: not even deterministic agents can perform free actions if (2) is true. The obstacle to freedom so construed is our finitude, not determinism or indeterminism. So even if one persists in claiming that freedom and responsibility require freely exercising antecedent control (thus making free will and moral responsibility impossible for finite agents), it is important to realize that indeterminism per se is not the source of this threat. According to the problem of moral luck, one kind of luck that threatens moral responsibility is constitutive luck: luck in becoming who we are. It might be argued that in not being capable of satisfying Haji's conception of freedom, we are subject to constitutive luck which is freedom- and responsibility-undermining. I think this line of argument is mistaken, but the point I will insist on here is that whatever one means by luck in this argument, it has no essential connection to indeterminism. The problem of constitutive luck is not a problem facing libertarians per se: it is a problem for anyone who thinks we are free and morally responsible. The problem of constitutive luck arises out of our finitude, not our being undetermined.

When unensured action is understood to refer to action over which we fail to (freely or merely) exercise antecedent control, (2) is problematic. Requiring mere antecedent control is unmotivated, and requiring free antecedent control makes freedom impossible for finite agents. But even supposing that this impossible condition is required, it is important to realize that indeterminism is not generating the problem: it is our finitude, not indeterminism that raises the specter of constitutive luck.

Indeed, I would argue that it is precisely our finitude and concerns about constitutive luck that lead libertarians to insist that some of our actions must be undetermined, if we are free and morally responsible. We, as finite agents, subject to the vagaries of time, simply cannot exercise antecedent control over all our actions. This leaves only two options: either events over which we have no control, in conjunction with the laws, determine what we do, or they don't. The second option, that the past and laws leave our actions undetermined, appears more conducive to freedom. If determinism is true, it seems that we lack the opportunity to exercise our abilities in ways different than we actually do (cf. Franklin n.d.a; van Inwagen 1983), and so our freedom and responsibility are significantly diminished; whereas, if indeterminism obtains at the moment of action, we have the opportunity do otherwise. According to libertarianism, we must allow that for some of our actions, it is open right up until the moment of choice what we will choose-otherwise our 
first actions will be determined, not by earlier free actions, by factors outside our control. By requiring indeterminism to occur at the moment of action, we secure a degree of independence from the past and laws, an independence that allows us to exercise our abilities in more than one way and thus, there and then in action, take a stand on the kind of person we will become. In such a case, our heredity and environment leave open (although presumably they restrict the possible options), up to the final moment, what we do. It is this openness that provides the needed space for agents to have free will.

I suspect that Haji, as well as many other philosophers, has thought this openness, which libertarians claim is so crucial for freedom, introduces luck because of the role that the effort of will plays in Kane's account. Haji develops the ensurance formulation of the luck argument specifically to undermine Kanean libertarianism. Recall that, on Kane's theory, in the history of a free agent, there are important moments of conflict within the agent's will in which she is torn between making the moral or prudential choice. The agent makes an effort of will to make the moral choice, but since this effort is indeterminate, she might still make the prudential choice. Whatever choice she ends up making will be undetermined. Kane's account suggests that the agent does something at $t_{1}$, makes an effort of will to resist temptation for example, but this action only indeterministically brings about the choice to resist temptation at $t_{2}$. Consequently, the agent lacks antecedent control over the choice to resist temptation at $t_{2}$ : she only has the power to do something that will nondeterministically bring about the choice to resist temptation at $t_{2}$. Moreover, it might seem that the agent's control is enhanced if the connection between the effort of will and resulting choice is deterministic. But if we relocate indeterminism, as I do, so that it occurs between non-actional mental events and action, for example between the businesswoman's reasons for making the effort to make the moral choice and her effort to make the moral choice, this worry disappears.

This is a subtle difference. To help bring it out, suppose for a moment that on my theory of action Kane's efforts of will do in fact precede choice. On Kane's account, unlike mine, indeterminism occurs after we make an effort of will and indeterminism effects whether we succeed in this effort; in fact, the presence of indeterminism diminishes our chances of success. We do everything we can to resist temptation, but because of indeterminism our best effort might still fail. On my account, however, if we make the effort of will to resist temptation, then we will choose to resist temptation and will resist temptation. ${ }^{21}$ It is open, until the last moment, what effort we make. We might make the effort to resist temptation or we might make the effort to succumb. Whichever effort we make is up to us, but whichever effort we make will guarantee that we make the corresponding choice, since the connection between these two actions is deterministic. Therefore, unlike Kane's theory it is not true that we do everything we can and are then forced to wait to see how

\footnotetext{
${ }^{21}$ This is of course too strong. After all, I might make this effort and then die before the effort culminates in a choice. The point is that assuming that these uncontested necessary conditions for making a choice obtain, e.g. I am alive, the earth has not blown up, etc., then if I make the effort of will to resist temptation, this guarantees that I make the choice to resist temptation, which in turn will guarantee that I resist temptation.
} 
indeterminism resolves itself. What is true is that everything we do not do leaves open what we will do. And this is what we, or at the least we libertarians, want.

\section{The rollback formulation}

van Inwagen (1983, pp. 128-129) initially dismissed as misguided arguments that employ the notion of luck in order to show that indeterminism diminishes control, but has recently changed his mind (van Inwagen 2000). In the present formulation, we are asked to imagine that an agent, Alice, is deliberating about whether to choose to tell the truth or to lie. van Inwagen writes, "Suppose, for example, that in some difficult situation Alice was faced with a choice between lying and telling the truth and that she freely chose to tell the truth-or, what is the same thing, she seriously considered telling the truth, seriously considered lying, told the truth, and was able to tell the lie she had been contemplating" (2000, p. 14). Since Alice had the ability to choose to tell the lie, the choice to tell the truth was undetermined (van Inwagen is assuming that the ability to do otherwise is incompatible with determinism): up until the moment of choice she could have chosen to tell the lie. ${ }^{22}$ Next we are asked to imagine that God has caused the world to "rollback" to precisely the state of the universe at the moment before Alice chose to tell the truth, let the world evolve from that point, and that we are in a position to observe this replay. Since Alice's choice is undetermined, she might choose to tell the lie or she might choose to tell the truth in the "replay." Suppose that God does this a thousand times: a thousand times he causes the world to rollback to precisely the moment before Alice made her choice and then allows things to proceed. Furthermore, imagine that, after watching 726 replays, in about half of the replays Alice has chosen to tell the truth and in the other half she has chosen to lie. After watching each of these replays, van Inwagen claims:

we shall be faced with the inescapable impression that what happens in the seven-hundred-and-twenty-seventh replay will be due simply to chance.... [W] hat other conclusion can we accept about the seven-hundred-and-twentyseventh replay (which is about to commence) than this: each of the two possible outcomes of this replay has an objective, 'ground-floor' probability of 0.5-and there's nothing more to be said? And this, surely, means that, in the strictest sense imaginable, the outcome of the replay will be a matter of chance. (2000, p. 15)

Unlike other formulations of the luck argument, van Inwagen does not stop here; rather he goes on to make it clear why luck is a threat to freedom: if an action $\varphi$ is a matter of luck, then no one has the ability to bring about $\varphi$ or the ability to prevent it. He explains, "If [Alice] was faced with telling the truth and lying, and it was a mere matter of chance which of these things she did, how can we say that - and this is essential to the act's being free-she was able to tell the truth and able to lie?

\footnotetext{
22 Van Inwagen slides between Alice's choosing to tell the truth and telling the truth. I will try to be a little more consistent and assume that it is Alice's choice that is under scrutiny.
} 
How could anyone be able to determine the outcome of a process whose outcome is a matter of objective, ground-floor chance?"23 (2000, p. 16). And, if Alice was not able to perform the action or perform some other action, then, according to van Inwagen, she was not free or morally responsible.

The two significant claims that we must evaluate are (1) if a choice is undetermined, then it is a matter of luck, and (2) if it is a matter of luck that event $E$ occurred, then no one was able to prevent or bring about $E$ at that time. Some commentators (Ekstrom 2003) have tried to argue that van Inwagen equivocates on the meaning of luck: in (2) he employs a notion of luck that is essentially inimical to control, but in (1) he employs an innocuous notion of luck. However, this charge does not stick. In fact, van Inwagen is clearer than many other proponents of the luck argument concerning exactly what he means by chance: an event is a matter of chance just in case the objective probability of its occurring is less than $1 .^{24}$ This should be relatively apparent from the passages quoted above. From the fact that there is an objective probability of less than 1 -specifically 0.5 - that Alice will choose to tell the truth, van Inwagen concludes that "in the strictest sense imaginable" the outcome is a matter of chance. If this indeed is what van Inwagen means by chance, then (1) is certainly true. All undetermined actions have an objective probability of less than 1 of occurring and so all their occurrences are a matter of chance.

But what about premise (2)? Is van Inwagen correct that if there is an objective probability of less than 1 that Alice will choose to tell the truth, then she does not have the ability to choose to tell the truth or to do something else, like choose to lie? To convince us of this, that no can have the ability to determine the outcome of an indeterministic process, van Inwagen offers the following case. He asks us to consider a situation in which the friend of a candidate running for public office knows some discreditable fact that, if revealed, will cost the candidate the election. The candidate asks his friend to promise not to reveal this fact. Suppose the friend knows (perhaps God told him) that there is an objective, ground-floor probability of 0.43 of his revealing the discreditable fact to the public, and an objective, groundfloor probability of 0.57 that he will remain silent. Is the friend in a position to promise the candidate that he will not reveal the fact? It seems not since of a million perfect duplicates of the friend, placed in exactly the same situation, $43 \%$ will reveal the secret and 57\% will remain silent. "But", van Inwagen goes on, "if [the friend believes] that [he is] able to keep silent, [he] should, it would seem, regard [himself] as being in a position to make this promise. What more [does he] need to regard [himself] as being in a position to promise to do $\mathrm{X}$ than a belief that [he is] able to do X? Therefore, in this situation, [he] should not regard [himself] as being able to keep silent" (2000, p. 17). Given the situation the friend finds himself in, he cannot

\footnotetext{
23 van Inwagen vacillates between claiming that undetermined action is "simply a matter of chance" and that undetermined action is "a matter of chance." I will assume that he offers his an argument as a defense of the latter, weaker claim.

24 This may actually be stronger than what van Inwagen argues for. He only commits himself to the claim that an event that has a probability of 0.5 is a matter of chance. He may think that once the probability reaches, say 0.9 , then it is no longer a matter of chance. However, as I am going to grant him (1), nothing of significance is effected by my, potentially, minor misinterpretation.
} 
promise the candidate he will remain silent and the best explanation of this, according to van Inwagen, is that he is not able to keep silent. This is a distinctive feature of van Inwagen's formulation of the luck argument: according to him, indeterminism calls into doubt what agents have the ability to do and thereby what agents are free to do.

Two points often overlooked by van Inwagen's critics are that, first, he rejects this argument and, second, that the aim of this argument is not to show that free will is incompatible with indeterminism - after all van Inwagen does not think this is the case-but to show that agent-causation is of no help in showing that indeterminism is compatible with free will. Agent-causalists sometimes offer the luck argument against their event-causal counterparts, trying to show that libertarians must adopt agent-causal libertarianism in order to address the worries raised by the luck argument. van Inwagen's argument aims to show that if indeterminism causes problems for event-causal libertarians it is also causes problems for agent-casual libertarians. And this point is, of course, compatible with believing that it is not a problem for either. Nonetheless, van Inwagen does think that this argument poses a major challenge for libertarians, a challenge that he does not know how to meet, and thus a challenge that pushes him towards his "mysterian" position.

I agree with both these points-that agent-causation is of no help here and that this argument fails. I will not press the first, except insofar as I will show that eventcausal libertarians do not have to appeal to agent-causation to handle this objection. But unlike van Inwagen, I know why this argument fails. Consider first the case of promising, which aims to bolster the rollback argument. The problem with this case is that it is importantly different from the typical kinds of situations in which libertarians think agents possess free will. The friend finds himself in a situation in which there are certain objective probabilities concerning what he will do at a later time and there is nothing he is now able to do to affect these probabilities. God reveals to him that later that day there is roughly a fifty-fifty chance that he will remain silent or reveal the secret. Perhaps in such a case the friend really does lack the ability to reveal the secret and the ability to remain silent, but whatever the correct answer is here this is not the kind of situations libertarian agents usually finds themselves in, nor is such a predicament forced on libertarians by the very nature of indeterminism.

There is a similar mistake here as there was in the ensurance formulation. Suppose that the friend refrains from revealing the secret at $t_{3}$ and that this action was undetermined. It is no part of the libertarian account that there was nothing the friend had the ability to do before $t_{3}$ to ensure that he kept silent at $t_{3}$. For example, the friend might have chosen, at $t_{1}$, to keep silent at $t_{3}$ and this earlier choice may well have raised the probability of his keeping silent at $t_{3}$ to 1 . But the friend lacks this ability in van Inwagen's imagined case: instead there is an objective, groundfloor probability concerning his revealing the secret and remaining silent and there is nothing the friend could have done to affect these probabilities. Whatever the friend does earlier in the day leaves unaffected what he will later do with respect to revealing the secret. van Inwagen, as did Haji, mistakenly locates indeterminism after choice and for this reason sees indeterminism as a threat to freedom and responsibility. 
van Inwagen's promising cases builds in assumptions about the location and role of indeterminism that libertarians are not committed to. In light of this disanalogy, premise (2) is left without a defense. But in addition to lacking support, there is good reason to think it is false. Elsewhere (Franklin n.d.b), I have offered the following preliminary account of abilities:

(A*) An agent $S$ has the ability to $\varphi$ at $t$ in $W$ only if there is a set of possible worlds $w$, that is such that, all the worlds in this set have the same laws of nature as $W, S$ 's intrinsic properties are sufficiently similar to her intrinsic properties in $W$, and $\mathrm{S} \varphi$-S.

As I argued there, just how large this set of worlds must be is difficult to specify, and it may well be relativized to the specific ability we are considering. The mere fact that there is a single world with the same laws of nature in which you make a full court basketball shot is insufficient to establish that you have the ability to make this shot. Rather, it seems that the existence of the ability requires there to be a larger range of worlds in which you successfully exercise the ability. However, in Alice's case there will be many worlds in which she makes each choice, and so we need not face this issue at present.

According to $\left(\mathrm{A}^{*}\right)$, Alice has both the ability to choose to tell the truth and the ability to choose to lie. This is because, for each choice there is a sufficiently large range of worlds in which the laws are the same, Alice's intrinsic properties are sufficiently similar to her intrinsic properties in the actual world (since indeterminism obtains, there will be many worlds in which these properties are identical), and she makes that choice. In case one worries that my theory of abilities is merely an ad hoc attempt to save libertarianism, observe that this is not an unusual result. Indeed, I have never come across an account of abilities that would vindicate van Inwagen's claim. Duggan and Gert (1967), Horgan (1979), Kaufman (1963), Lehrer (1976) Locke (1974), and Mele (2003) all offer accounts of ability in which Alice has both the ability to choose to tell the truth and the ability to choose to lie (and, importantly, many of these philosophers are compatibilists). Therefore, van Inwagen's contention concerning the supposed relationship between chance and abilities is not only left undefended (in light of the above disanalogy), but it is also dubious.

I think van Inwagen is led astray by a subtle confusion. What would call into question Alice's abilities is if her exercising her ability to choose to tell the truth was consistent with her not telling the truth. That is, if the probability of her telling the truth rather than lying was fifty-fifty even after she exercised her ability to choose to tell the truth, we would conclude that this is no ability at all. But this is not the story the libertarian tells. What is undetermined is Alice's exercising her ability to choose to tell the truth. It is perfectly consistent with event-causal libertarianism that the exercising of the ability deterministically brings about her telling the truth. The rollback formulation, like the ensurance formulation, confuses where indeterminism occurs in the action-sequence and, as a result, appears to show that indeterminism is a threat to control. But once we clearly distinguish where the libertarian locates indeterminism, and what it is to have an ability, we are left with little to no reason for thinking that indeterminism introduces a kind of luck or 
chance that is incompatible with an agent possessing abilities and hence being free and morally responsible.

\section{Explanatory formulations}

Explanatory formulations of the luck argument maintain that luck is introduced into the action-sequence due to the unavailability of a certain kind of explanation. It is because the feature that would allow us to give such an explanation is missing that the agent is subject to luck, and, of course, the presence of luck entails that the action in question is not free. Once again, it seems that libertarians are committed to the existence of actions that are both free and unfree.

At times it has been suggested that undetermined action is essentially irrational action, or, at the very least, cannot be given a rational explanation (Ayer 1954). But this is false. Two central features of a successful rational explanation are that the explanation make intelligible to us why the agent acted as he did, and that the features appealed to which render the action intelligible play a causal role in bringing about the action (Davidson 1963; Mele 1992). Since my event-causal libertarian account requires that reasons, or at least the agent's taking there to be reasons, play a central causal role in bringing about action, it has a straightforward way of providing reason-explanations: appeal to the reasons that the agent took himself to have that played a role in bringing about his action. ${ }^{25}$ Consider a thief who successfully resists the temptation to rob the poor box in a local parish. ${ }^{26} \mathrm{We}$ might ask: why did the thief refrain from stealing? To which the libertarian can answer: the thief recalled that he had promised his mother on her death bed to live a good life and that stealing from the poor is inconsistent with this promise. Moreover, these reasons, or the thief's taking there to be these reasons, played a causal role in bringing about his refraining. So, event-casual libertarians can, in a straightforward way, provide reason-explanations for undetermined actions.

But there is another kind of explanation that has played a prominent role in the explanatory formulation of the luck argument, and it is less clear that it can apply to undetermined actions. The kind of explanation I speak of is contrastive explanation: explanations of why the agent $\varphi$-ed rather than $\psi$-ed. According to this formulation of the luck argument, an agent's undetermined action $\varphi$ is a matter of luck because there is no contrastive explanation of why the agent performed this action rather than another.

\footnotetext{
25 Whether or not reasons are ever actually causes of behavior is disputed. Those who maintain that reasons are propositions (Scanlon 1998) or states of affairs (Dancy 2003) are likely to argue that reasons cannot be causes, whereas those who take reason to be mental states, such as desire-belief pairs (Davidson 1963), often accord reasons a causal role in the genesis of intentional action. Nonetheless, these former accounts can readily accommodate the Davidsonian claim (if they so wish) that reasons are causes, by according the mental state of the agent taking there to reasons that favor his $\varphi$-ing a causal role in bringing about his $\varphi$-ing. Although strictly speaking reasons are not causes on such an account, the mental state of taking there to be reasons is capable of playing the role that Davidson accords to reasons.

26 This often discussed case is taken from van Inwagen (1983, pp. 127-128).
} 
Mele (1999a, b, 2005, 2006) has been the most forceful and persistent proponent of the explanatory formulation. ${ }^{27}$ Mele "illustrates" this worry by considering a goddess Diana who is creating agents that satisfy libertarianism. As she considers her agents who sometimes perform undetermined actions, she worries that indeterminism is a threat to their control.

Her worry, more specifically, is that if the difference between the actual world, in which one of her agents judges it best to $A$ straightaway and then, at $t$, decides accordingly, and any possible world with the same past up to $t$ and the same laws of nature in which he makes an alternative decision while the judgment persists is just a matter of luck, then he does not freely make that decision in that possible world, $W$. Diana suspects that his making that alternative decision rather than deciding in accordance with his best judgment - that is, the difference between $W$ and the actual world-is just a matter of bad luck or, more precisely, of worse luck in $W$ for the agent than in the actual world. After all, because the worlds do not diverge before the agent decides, there is no difference in them to account for the difference in decisions. (Mele 2006, p. 8)

It is very important to be clear on what Mele is claiming: he is not claiming that the agent's decision in either the actual world or $W$ is just a matter of luck. What is just a matter of luck is a comparative fact between the worlds: the cross-world difference between the actual world and $W$. What is just a matter of luck is that the agent $\varphi$-ed-as he did in the actual world—rather than $\psi$-ed-as he did in $W .^{28}$ But Mele does maintain that if the cross-world difference is just a matter of luck, then each action in each world is partly a matter of luck, and apparently enough of a matter of luck to preclude the possibility of the agent being free or morally responsible for either action (Mele 2006, p. 8).

Put in schematic form, Mele's argument runs as follows:

1. If an agent $S$ performs an undetermined action $\varphi$ at $t$ in $W$ and there is some world $W^{*}$ that shares the same laws and past as $W$ up to $t$, but in which $S \psi$-s, then there is nothing that accounts for the difference between $W$ in which $S \varphi$-ed and $W^{*}$ in which she $\psi$-ed (where $\psi$-ing includes not $\varphi$-ing).

2. If nothing accounts for this difference, then the difference is just a matter of luck.

3. If the difference is just a matter of luck, then it is partly a matter of luck that she $\varphi$-ed in $W$ and partly a matter of luck that she $\psi$-ed in $W^{*}$.

4. If an action is partly a matter of luck, then the action is not free.

5. Therefore, if an action is undetermined, then it is not free.

It would seem that libertarians must reject at least one of the first three premises. It is hard to believe that an action that is partly a matter of luck could also be free and

\footnotetext{
27 Others who have raised this worry include Haji (1999) and Waller (1988).

28 This is a point that is nearly universally missed by Mele's critics (see O'Connor 2007; Pereboom 2007).
} 
thus one for which an agent is morally responsible. ${ }^{29}$ Since (5) is entailed by (1)(4), libertarians must reject at least one of the first three premises.

Let us begin by considering premise (2). Mele claims that if nothing accounts for the difference, if there is no explanation of why the agent $\varphi$-ed rather than $\psi$-ed, then the difference is just a matter of luck. But why think this? Assuming that luck is essentially contrary to control, why think that the lack of contrastive explanation indicates a lack of control? It is well known that explanations introduce pragmatic and epistemic considerations, considerations that do not themselves tightly track control (cf. Clarke 2003, Chap. 3). Hitchcock's (1999) influential theory of contrastive explanation makes it clear that whether one can give a contrastive explanation of some phenomenon $p$ depends, partly, on the knowledge or beliefs of the person to whom you are giving the explanation. According to Hitchcock, we cannot give contrastive explanations of why $p$ rather than $q$ to a person who knows everything there is to know about $p$ and $q$, and this whether or not $p$ comes about deterministically or indeterministically (Hitchcock 1999, p. 598). Consequently, if some observer knows everything there is about my $\varphi$-ing in $W$ and my $\psi$-ing in $W^{*}$, then there is no available contrastive explanation that can be offered to her for why I $\varphi$-ed rather than $\psi$-ed, even if my action in $W$ is determined. But it is doubtful that the observer's mere possession of this knowledge could diminish my control over $\varphi$. Control is fundamentally a metaphysical matter and thus does not depend on the presence or absence of these pragmatic or epistemic conditions.

There is reason, then, to think that lack of (contrastive) explanation does not tightly track lack of control, and, therefore, assuming that luck is essentially contrary to control, there is little reason to think that lack of explanation introduces luck. But it turns out, according to Mele's definition of luck, that (2) must be true: (2) turns out to be little more than a tautology. Anticipating that someone might object to his argument by questioning the meaning of 'luck', Mele makes it clear what he has in mind by this notion. In response to the question, "What is luck?" he answers:

Well, if the question why an agent exercised his agent-causal power at $t$ in deciding to $A$ rather than exercising it at $t$ in any of the alternative ways he does in other possible worlds with the same past and laws of nature is, in principle, unanswerable - unanswerable because there is no fact or truth to be reported in a correct answer, not because of any limitations in those to whom the question is asked or in their audience - and his exercising it at $t$ in so deciding has an effect on how his life goes, I count that as luck for the agent.... (2006, p. 70)

So, according to this characterization of luck, it turns out that luck is the absence of anything that accounts for the difference between these two worlds. If nothing accounts for the difference, then, by definition, the difference is just a matter of luck. This definition of luck calls into question the role that this notion plays in establishing Mele's conclusion. The initial worry about premise (2) was that, on an intuitive level, luck involves the absence of or diminution of control, but, as argued

\footnotetext{
${ }^{29}$ Nonetheless, Mele offers a libertarian account that has just this result (see Mele 2006, Chap. 5).
} 
above, the absence of explanation (of any kind) does not entail an absence or diminution of control. Mele has tried to forge a dubious connection between luck and the absence of a contrastive explanation. Perhaps luck does always involve a lack of a certain kind of explanation, but it must involve more than this in order to diminish control.

Mele might respond by arguing that he is giving a stipulative definition of luck rather than an analysis of the intuitive notion. According to his definition of luck, luck enters the picture when there is a lack of explanation. But now it is open to the libertarian to wonder why luck, as defined by Mele, is a threat to free will and moral responsibility. The essence of the initial problem remains: as the stipulative notion only indicates a lack of explanation, there is no reason to think that control is diminished.

A better route for Mele, one that he partly suggests, is to drop the claim that the difference is just a matter of luck, leave the notion of luck unanalyzed, and argue instead that since nothing accounts for the difference between worlds, each action is partly a matter of luck-where luck here is understood in an intuitive sense. ${ }^{30}$ To make this move clear it will be helpful to rewrite Mele's argument according to my suggested presentation:

$1 *$ If an agent $S$ performs an undetermined action $\varphi$ at $t$ in $W$ and there is some world $W^{*}$ that shares the same laws and past as $W$ up to $t$, but in which $S \psi$-s, then there is nothing that accounts for the difference between world $W$ in which $S \varphi$-ed and $W^{*}$ in which she $\psi$-ed.

$2 *$. If nothing accounts for the difference, then it is partly a matter of luck that she $\varphi$-ed in $W$ and partly a matter of luck that she $\psi$-ed in $W^{*}$.

$3^{*}$. If an action is partly a matter of luck, then the action is not free.

$4^{*}$. Therefore, if an action is undetermined, then it is not free.

Premise (2) from above drops out as does appeal to Mele's definition of luck: rather than arguing from the fact that the difference is just a matter of luck to the claim that each action is partly a matter of luck, Mele argues directly from the fact that nothing accounts for the difference to the claim that each action is partly of matter of luck. The crucial claims for the libertarian to dispute become $\left(1^{*}\right)$ and $\left(2^{*}\right)$.

The good news for the libertarian is that $\left(1^{*}\right)$ and $\left(2^{*}\right)$ are both highly questionable. Consider $\left(1^{*}\right)$ first. Can there be contrastive explanations of outcomes that are undetermined? There is no uncontroversial answer to this question, but Hitchcock (1999), to my mind, has made a strong case that there can be such explanations. To oversimplify, he provides a probabilistic model of explanation under which condition $A$ is explanatorily relevant to $E$, if $A$ raises the probability of E's occurring. ${ }^{31}$ Paying close attention to the role that presuppositions play in explanatory contexts, he suggests that an explanation can be technically correct, e.g.

\footnotetext{
${ }^{30}$ Mele (2006, p. 70) is willing to concede that 'luck' is not the right label for the fact that nothing accounts for the difference. He thinks, however, that the mere fact that nothing accounts for the difference, whether or not it smuggles in luck, is worrisome.

31 This is a sufficient condition for explanatory relevance, but not according to Hitchcock (1999) a necessary one. Note that probabilistic explanatory models work just as well in deterministic scenarios. In these cases the explanatorily relevant condition raises the probability to 1 .
} 
it cites a condition that raises the probability of E's occurring, but nonetheless pragmatically defective "because it does not provide any explanatory information over and above what is already presupposed" (Hitchcock 1999, p. 598). So a contrastive explanation of the fact that $E$ rather than $F$ is successful if it cites a condition $A$ that raises the probability of $E$ and $A$ is not presupposed. For the most part, what is presupposed will be a function of what the parties who are engaged in the "language game" already know about $E$ and $F$. But Hitchcock claims that there is always at least one particular presupposition at play in contrastive explanation contexts: the disjunction of the contrasts. Supposing that the contrastive fact to be explained is that the thief decided to refrain rather than steal, we are presupposing that either the thief decided to refrain or decided to steal. That is, we are presupposing that one or another of these happened but not both (the disjunction here is understood exclusively). Assuming that Hitchcock is right about these points, we can provide a contrastive explanation of why the thief decided to refrain rather than steal by citing a condition $A$, which is not presupposed and raises the probability of his deciding to refrain. Presumably the thief's reasons for refraining raised the probability of his refraining. It is more likely that the thief would decide to refrain in the presence of these reasons than in their absence. In response to the question why the thief decided to refrain rather than steal, we can cite the reasons he had for this decision. ${ }^{32}$

Hitchcock's account is admittedly controversial and some will dispute whether the above is a genuine contrastive explanation. ${ }^{33}$ The point in appealing to Hitchcock's account is to make it apparent that libertarians can arguably provide contrastive explanations of undetermined actions. Interestingly, Mele appears willing to grant all this, but still insists that there is a problem for the libertarian. He writes, "However, it is not debatable that if worlds $W 1$ and $W 2$ do not diverge until $t$, there is no difference between the world segments those worlds share to account for or explain the difference at $t$. No claim about contrastive explanation that is not entailed by this one-and therefore no debatable claim about it—needs to be made for the purposes of posing the problem of present luck for conventional libertarianism" (2006, p. 73). I find this passage puzzling. Consider the conditional claim, "If worlds $W 1$ and $W 2$ do not diverge until $t$, there is no difference between the world segments those worlds share to account for or explain the difference at $t$." Clearly this is true, but it is also trivial. If there is no difference between $W 1$ and $W 2$ before $t$, then there is no difference between $W 1$ and $W 2$ before $t$ that explains the difference in outcomes. This claim is undoubtedly true, yet it does not follow that nothing explains the difference. Mele controversially assumes that we can provide a contrastive explanation of the difference between the worlds at $t$ only if there is a difference between the worlds at some time before $t$. But the libertarian need not and ought not concede this. We can, arguably, explain the difference between worlds at the time of the thief's decision even though there is no difference between the

\footnotetext{
32 Again, I am simplifying Hitchcock's account for present purposes. The thief's reasons can explain the contrastive fact only if these reasons raise the probability of his deciding to refrain more than they raise the probability of his deciding to steal (Hitchcock 1999, p. 602).

33 See Lewis (1986a, b), Railton (1978), and Salmon (1981).
} 
worlds before this moment. The difference is explained by citing the thief's reasons which raised the probability of his deciding to refrain. So rather than showing that libertarians cannot provide contrastive explanations of undetermined actions, Mele only shows that libertarians cannot provide a particular kind of contrastive explanation of undetermined actions - one that appeals to a difference before the time of the action in question. They cannot provide the latter kind of explanation because there is no difference before the time of the action in question, and hence there is no difference before the time of the action in question to explain the difference in outcome. But this inability of libertarianism does not seem to raise any significant worries for their accounts.

Even supposing that Mele establishes $\left(1^{*}\right),\left(2^{*}\right)$ is dubious and for the same reasons that (2) of the original formulation of the argument was dubious. As argued before, lack of contrastive explanation does not indicate a lack of control. Whether or not an explanation can be given depends on what the explainee knows or is assuming, and precisely because the availability of explanation depends on these epistemic and pragmatic conditions, explanation does not tightly track control: whether I control some outcome does not depend on what some other person knows or assumes. So, even if nothing accounts for the difference in outcomes between worlds, it does not follow that the agent is subject to luck or diminished control.

Mele's explanatory formulation of the luck argument is subject to multiple objections. First, premise $\left(1^{*}\right)$ is simply undefended and while many have indeed thought that contrastive explanations cannot be given for undetermined events, Hitchcock's account calls this claim into question. To clarify, I do not take myself to have shown beyond doubt that contrastive explanations are available for undetermined events, but only that there are sophisticated theories of explanation under which this is possible. However, as we saw, Mele focuses on a particular kind of contrastive explanation: one that explains the difference in outcomes by appealing to a difference in prior conditions. And Mele is correct that it is not debatable whether this kind of contrastive explanation is available. However, even if one grants that free and morally responsible action must be capable of being contrastively explained, it does not follow that this specific kind of contrastive explanation is required.

$(2 *)$ also faces problems as it assumes that there is a tight link between control and explanation: namely there is no free will without contrastive explanation. I argued that the conditions under which an action is controlled and the conditions under which an explanation is available differ to a sufficient degree to call into question whether this tight link obtains. Since the availability of contrastive explanations depends on pragmatic and epistemic conditions that are irrelevant to control, it is possible for one to control an event even though the event's occurrence does not admit of a certain explanation.

\section{Interlude}

The luck argument has proved to be a constant source of worries for philosophers. It is often assumed that the absence of determinism entails mere randomness, and 
randomness is hardly conducive to control. I hope to have shown that this conclusion is unfounded. There is little reason for thinking that indeterminism involves a kind of luck or randomness that poses any threat to our being free and morally responsible. But it does not follow that indeterminism is not inimical to control. For there is another argument-one which eschews any mention of luckthat purports to show that indeterminism is incompatible with free will. Therefore, a successful defense of the coherence of libertarianism must go on to show that this argument is also unsound.

\section{The Mind argument}

The Mind argument is a direct argument for the incompatibility of indeterminism with free will and moral responsibility. The luck argument uses a middleman to try to establish this conclusion. It first attempts to show that indeterminism entails the presence of luck and then that luck entails the absence of control. The Mind argument drops this middleman and argues that free will and moral responsibility are directly incompatible: it claims that indeterminism per se, regardless of any putative connection to luck, entails the absence of the degree of control necessary for free will and moral responsibility.

There are two key assumptions in the Mind argument. The first is that someone is free with respect to action $\varphi$ only if he had a choice about $\varphi$. The second is that the following inference rule BETA is valid:

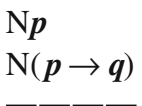

$\mathrm{Nq}$

where ' $\mathrm{N} p$ ' is to be read ' $p$ and no one has or ever had a choice about whether $p$. . 34 With these assumptions in place, van Inwagen argues that "no one has any choice about that which is undetermined" (1983, p. 142). He defends this claim by asking us to imagine a device the salient features of which are a red light, a green light and a button. When one presses the button there is an objective probability of 1 that either the red light or green light will flash, but an objective probability of less than 1 that the red light will flash and an objective probability of less than 1 that the green light will flash. van Inwagen writes, "Now suppose that you must press the button on this mechanism. Have you any choice about which of the lights will flash?

\footnotetext{
34 As McKay and Johnson (1996) have shown, and van Inwagen (2000) conceded, BETA is invalid. Transfer-principles, like BETA, have played an important role not just in the Mind argument, but also in the consequence argument for incompatibilism about free will and determinism. Finch and Warfield (1998) offer a way to remedy BETA so that it can be employed in a sound argument for incompatibilism about free will and determinism but, interestingly, is useless for reformulating the Mind argument. See Nelkin (2001), however, for an argument that shows that even Finch and Warfield's revised transfer principle raises trouble for libertarians. I have elected not to discuss this interesting debate as I think that the Mind argument has intuitive force apart from any appeal to controversial inference rules. For this reason I ignore worries about the validity of BETA and take issue instead with the second premise of the argument.
} 
It seems obvious that you have no choice about this" (1983, p. 142). The conclusion van Inwagen draws from this example is that no one has any choice about which light will flash, given the button is pressed. Suppose you press the button and the red light flashes. According to van Inwagen, it is clear, since the connection between the button and the particular light flashing is indeterministic, that you had no choice about whether the red light flashed given that the button was pressed. With these pieces in place, van Inwagen has the ingredients for a powerful argument that free will is incompatible with indeterminism.

Return to the case of the thief who chose to refrain from robbing the poor box discussed in Sect. 8. In accordance with event-causal libertarianism, let us assume that the thief's refraining, call it $R$, was nondeterministically brought about by some mental state $D B$ that favored it. It follows from this assumption that it was possible, given the past and laws, that $D B$ not have caused $R$. Suppose that had $D B$ not caused $R$, then the thief would have chosen to rob the poor box, call this $R^{*}$, and, let us further assume, that this action would have been nondeterministically brought about by a different mental state $D B^{*}$ that favored $R^{*}$. Finally, assume that the thief had no choice about $D B$ and $D B^{*} .{ }^{35}$ From our reflections on the simple device above, it follows that no one, let alone the thief, had a choice about whether $R$ follows $D B$, since $R$ followed nondeterministically from $D B$ and no one has a choice about that which is undetermined. But then according to van Inwagen's inference rule BETA, it follows that the thief had no choice about $R$ :

1. $\mathrm{N} D B$

2. $\mathrm{N}(D B \rightarrow \mathrm{R})$

3. NR.

If the thief had no choice about $D B$ and he had no choice about $R$ 's following $D B$, then, according to rule BETA, he had no choice about $R$ itself. It follows from our assumption about free action that the thief's refraining was not free. All these remarks generalize to all agents and all undetermined actions. Therefore, undetermined action cannot be free action.

I remain unconvinced. One problem with van Inwagen's argument is that he never tells us what it is to have a choice about an action. In fact, he does not even specify an essential feature of having such a choice. This becomes exasperating when the action in question is itself a choice: what is it to have a choice about a choice? But there are deeper problems. I will, with van Inwagen, assume that the thief does not have a choice about $D B$ or $D B^{*}$. But what about the complex state of affairs of $D B$ 's causing $R$ : does the thief have a choice about this? van Inwagen claims that he cannot since $D B$ 's causing $R$ was undetermined, and no one can have a choice about that which is undetermined, as the device example showed. But this example establishes far less than van Inwagen thinks. What the example shows, at

\footnotetext{
35 This assumption is harmless as the thief could only have had a choice about $D B$ or $D B^{*}$, if he performed some earlier action which itself would have been brought about by yet earlier mental states. We could then raise the same questions about this earlier action and these earlier mental states. Someone might again insist that the agent had a choice about these still earlier metal states. But this cannot go on forever and we will eventually discover the thief's "initial" mental states for which he had no choice.
} 
most, is that if one performs an action (pressing a button) and a consequence of that action comes about nondeterministically (the red light flashes), then one does not have a choice about that consequence. Like Kane's account, the indeterminism occurs after action, rather than just prior to or at the moment of action. I am willing to concede that van Inwagen is correct that if one's action brings about an outcome nondeterministically, then he does not have a choice about the outcome, but as we have seen this point has little relevance for libertarianism. What van Inwagen needs to show is that if the connection between one's basic action and the prior nonactional mental state is indeterministic, then we cannot have a choice about the basic action. The device example does nothing to establish this. $D B$ is not an action of the thief's, but rather is the non-actional mental event that brings about the thief's action. ${ }^{36}$ The second premise, $\mathrm{N}(D B \rightarrow R)$ is, consequently, left undefended.

But there is another problem with van Inwagen's argument. His claim that the thief does not have a choice about whether $R$ follows $D B$ does not seem well-formed. To ask whether the thief had a choice about whether $D B$ brought about $R$ is, on the face of it, a rather awkward question since, according to the event-causal theory of action, $D B$ 's bringing about $R$ just is the thief's exercising control over $R$. According to the event-casual theory of action, what it is for an agent to exercise control over some event $E$ is for $E$ to be caused, in the appropriate way, by some agent-involving mental event $E^{*}$. So what might the thief's having a choice about whether he exercised control over $R$ come to? An agent's exercising control over some action $\varphi$ is not something she does in addition to $\varphi$-ing: it is not an action. She doesn't first perform the action exercising control over $\varphi$, which then in turn brings about $\varphi$. Exercising control is a relation between an agent, or agent-involving mental events, and some other event. Compare the following events. The thief's choice to refrain from robbing the poor box and the thief's exercising control over his choice to refrain. I would argue that these events occur simultaneously and that the thief's having a choice about whether he exercises control over his choice to refrain just is his having a choice about whether he chooses to refrain. If this is correct, then we must give symmetrical answers to the question of whether the thief had a choice about whether $R$ followed $D B$ and whether the thief had a choice about $R$.

van Inwagen's device example fails to show that the thief lacks a choice about whether $R$ follows $D B$, and so, assuming the above symmetry, he fails to give us any reason to deny that the thief had a choice about $R$. Moreover, there are reasons for thinking that the thief had a choice about $R$ and thereby a choice about whether $R$ follows $D B$. Nothing about the thief's choice prevents us from saying that he had the ability to choose to refrain from robbing the poor box and the ability to choose to rob the poor box. As we have seen above, agents can have the ability to $\varphi$, even when $\varphi$ 's occurring is indeterministic, and there is nothing about $\varphi$ 's being indeterministic that would rob an agent of the opportunity to exercise his ability to $\varphi$. In light of these

\footnotetext{
36 I believe that something like this mistake may very well be behind van Inwagen's rollback argument. Consider van Inwagen's question, "How could anyone be able to determine the outcome of a process whose outcome is a matter of objective, ground-floor chance?" (2000, p. 16). This sounds an awful lot like: How can someone do something now to determine something later, if it is undetermined whether the later thing occurs. If this interpretation is sound, then we have yet another reason to reject the rollback argument.
} 
considerations, it seems possible that the thief had a choice about refraining from robbing the poor box-this action was up to him. He had the ability and opportunity to choose to refrain from robbing the poor box and he had the ability and opportunity to choose to rob the poor box, and hence he had a choice about choosing to refrain from robbing the poor box. Consequently, if my point about symmetry is correct, the thief also had a choice about whether $R$ followed from $D B$.

van Inwagen, like many of the defenders of the luck argument, mistakes the location of indeterminism in the event-causal libertarian's account of action. ${ }^{37}$ By assuming that indeterminism occurs after action, he is able to argue that indeterminism, so located, is inimical to control. But once we carefully distinguish this mistaken assumption about the location of indeterminism from where libertarians actually do (or at least should) locate it, we see that there is no reason to think that indeterminism, located at such a juncture, would diminish control.

\section{Conclusion}

In this paper I have strived to allay worries about the compatibility of indeterminism with free will and moral responsibility. I have argued that the Mind argument and the many formulations of the luck argument are unsound. A recurring mistake in these arguments concerns the exact location of indeterminism. Many of these arguments (the ensurance formulation, rollback formulation, and Mind argument) assume that indeterminism occurs after choice or action, and I have argued that this mistake accounts for much of the force of these arguments. If trying our best to overcome temptation leaves open whether we will do wrong, then we do indeed seem subject to control-diminishing luck. But this is not the libertarian picture. According to libertarianism (at least my version), what we do need not leave open what we bring about. Rather, indeterminism is to be located at the moment of action so that what we do not do leaves open what we will do. What is left open is whether we try to resist temptation-not whether our trying is successful.

The remaining two formulations of the luck argument make different but no less crippling mistakes. The Hume-Hobart formulation mistakenly assumes that causation entails necessitation. On the basis of this assumption the argument proceeds to show that undetermined events must be uncaused. However, this assumption is unsupported and dubious. Consideration from both the nature of causation and quantum physics supports the possibility of nondeterministic causation.

The explanatory formulation mistakenly assumed both that undetermined actions cannot be contrastively explained and that free action requires the availability of contrastive explanation. There are, however, sophisticated theories of contrastive explanation under which we can contrastively explain undetermined action. While these accounts are contentious, they at least place the ball back into Mele's court. Moreover, even if Mele is correct that undetermined actions cannot be contrastively

\footnotetext{
37 As before, this might be unfair to van Inwagen as some event-causal libertarians have themselves mistaken the proper location of indeterminism in the action-sequence. If van Inwagen has such accounts in mind, then his argument, for all I have argued, may well have purchase on these theories. My claim is that it leaves my own account untouched.
} 
explained, he is wrong to think that such explanations are required for free will and moral responsibility. As the availability of explanation depends on pragmatic and epistemic considerations, there is reason to think that explanation does not tightly track control: we can exercise a sufficient degree of control over an event even if the occurrence of the event cannot be contrastively explained.

The luck and Mind argument give us little reason to think that indeterminism is a threat to free will and moral responsibility. Libertarianism is thus vindicated from the charge of incoherence: indeterminism is compatible with free will and moral responsibility. What remains to be seen is whether indeterminism is necessary for free will and moral responsibility, but this must wait for another occasion.

Acknowledgments This paper grew out of a graduate seminar, taught by John Fischer at the University of California, Riverside, Fall 2006. I am grateful to the participants of that seminar, especially Joshua Hollowell and Neal Tognazzini, for their many stimulating conversations. I am especially grateful to John Fischer, not just for his guidance throughout this wonderful course, but also for his penetrating feedback on subsequent drafts of this paper. I would also like to express my gratitude to an anonymous referee of this journal for helpful feedback.

Open Access This article is distributed under the terms of the Creative Commons Attribution Noncommercial License which permits any noncommercial use, distribution, and reproduction in any medium, provided the original author(s) and source are credited.

\section{References}

Anscombe, G. E. M. (1971). Causality and determination. New York: Cambridge University Press.

Ayer, A. J. (1954). Freedom and necessity. In Philosophical essays (pp. 3-20). New York: St. Martin's Press.

Bishop, J. (1989). Natural agency: An essay on the causal theory of action. New York: Cambridge University Press.

Campbell, C. A. (1951). Is 'freewill' a pseudo-problem? Mind, 60, 446-465.

Clarke, R. (2000). Modest libertarianism. Philosophical Perspectives, 14, 21-46.

Clarke, R. (2003). Libertarian accounts of free will. New York: Oxford University Press.

Clarke, R. (2004). Reflections on an argument from luck. Philosophical Topics, 32, 47-64.

Dancy, J. (2003). Practical reality. Oxford: Oxford University Press.

Davidson, D. (1963). Actions, reasons, and causes. Journal of Philosophy, 60, 685-700.

Dennett, D. (1978). On giving libertarians what they say they want. In Brain storms: Philosophical essays on mind and psychology (pp. 286-299). Montgomery: Bradford books.

Double, R. (1991). The non-reality of free will. New York: Oxford University Press.

Duggan, T., \& Gert, B. (1967). Voluntary abilities. American Philosophical Quarterly, 4, 127-135.

Ekstrom, L. W. (2000). Free will: A philosophical study. Boulder, CO: Westview Press.

Ekstrom, L. W. (2003). Free will, chance, and mystery. Philosophical Studies, 113, 153-180.

Finch, A., \& Warfield, T. (1998). The Mind argument and libertarianism. Mind, 107, 515-528.

Fischer, J. M. (1995). Libertarianism and avoidability: A reply to Widerker. Faith and Philosophy, 12, 119-125.

Fischer, J. M., \& Ravizza, M. (1998). Responsibility and control: A theory of moral responsibility. New York: Cambridge University Press.

Franklin, C. E. (n.d.a). The problem of enhanced control. Unpublished Manuscript.

Franklin, C. E. (n.d.b). Strawsonian libertarianism. Ph.D. Dissertation. University of California, Riverside.

Ginet, C. (1990). On action. New York: Cambridge University Press.

Haji, I. (1999). Indeterminism and Frankfurt-type examples. Philosophical Explorations, 1, 42-58. 
Haji, I. (2001). Control conundrums: Modest libertarianism, responsibility, and explanation. Pacific Philosophical Quarterly, 82, 178-200.

Hitchcock, C. (1999). Contrastive explanation and the demon of determinism. British Journal of the Philosophy of Science, 50, 585-612.

Hobart, R. E. (1934). Free will as involving determination and inconceivable without it. Mind, 43, 1-27.

Horgan, T. (1979). 'Could', possible worlds, and moral responsibility. Southern Journal of Philosophy, $17,345-358$.

Hume, D. (2000). A treatise of human nature (D. F. Norton \& M. J. Norton, Eds.). New York: Oxford University Press.

Kane, R. (1985). Free will and values. New York: State University Press of New York.

Kane, R. (1996). The significance of free will. New York: Oxford University Press.

Kane, R. (1999). Responsibility, luck, and chance: Reflections on free will and indeterminism. Journal of Philosophy, 96, 217-240.

Kaufman, A. S. (1963). Ability. Journal of Philosophy, 50, 537-551.

Lehrer, K. (1976). Can in theory and practice: A possible worlds analysis. In M. Brand \& D. Walton (Eds.), Action theory (pp. 242-271). Dordrecht: D. Reidel Publishing Company.

Lewis, D. K. (1986a). Causal explanation. In Philosophical papers (Vol. 2, pp. 214-240). New York: Oxford University Press.

Lewis, D. K. (1986b). Chancy causation. In Philosophical papers (Vol. 2, pp. 175-184). New York: Oxford University Press.

Locke, D. (1974). Natural powers and human abilities. Aristotelian Society Proceedings, 74, 171-187.

McCann, H. J. (1998). The works of agency: On human action, will and freedom. Ithaca: Cornell University Press.

McKay, T., \& Johnson, D. (1996). A reconsideration of an argument against incompatibilism. Philosophical Topics, 24, 113-122.

Mele, A. R. (1992). Springs of action. New York: Oxford University Press.

Mele, A. R. (1999a). Ultimately responsibility and dumb luck. Social Philosophy and Policy, 16, 274-293.

Mele, A. R. (1999b). Kane, luck, and the significance of free will. Philosophical Explorations, 2, 96-104.

Mele, A. R. (2003). Agents' abilities. Noûs, 37, 447-470.

Mele, A. R. (2005). Libertarianism, luck, and control. Pacific Philosophical Quarterly, 86, 381-407.

Mele, A. R. (2006). Free will and luck. New York: Oxford University Press.

Nelkin, D. (2001). The consequence argument and the Mind argument. Analysis, 61, 107-115.

Nowell-Smith, P. (1948). Free will and moral responsibility. Mind, 57, 45-61.

O'Connor, T. (2000). Persons and causes: The metaphysics of free will. New York: Oxford University Press.

O'Connor, T. (2007). Is it all just a matter of luck? Philosophical Explorations, 10, 157-161.

Pereboom, D. (2001). Living without free will. New York: Cambridge University Press.

Pereboom, D. (2007). On Alfred Mele's Free will and luck. Philosophical Explorations, 10, 165-172.

Railton, P. (1978). A deductive-nomological model of probabilistic explanation. Philosophy of Science, 45, 206-226.

Salmon, W. C. (1981). Scientific explanation and the causal structure of the world. Princeton: Princeton University Press.

Scanlon, T. M. (1998). What we owe to each other. Cambridge: Harvard University Press.

Smart, J. C. C. (1961). Free-will, praise and blame. Mind, 70, 291-306.

Smilansky, S. (2000). Free will and illusion. New York: Oxford University Press.

van Inwagen, P. (1983). An essay on free will. Oxford: Clarendon Press.

van Inwagen, P. (2000). Free will remains a mystery. Philosophical Perspectives, 14, 1-19.

Velleman, J. D. (2000). The possibility of practical reason. New York: Oxford University Press.

Waller, B. (1988). Free will gone out of control: A review of R. Kane's Free will and values. Behaviorism, 16, 149-157. 